\title{
lodide-photocatalyzed Reduction of Carbon Dioxide to Formic Acid with Thiols and Hydrogen Sulfide
}

\author{
Mateo Berton, ${ }^{[a]}$ Rossella Mello, ${ }^{[a]}$ María Elena González-Núñez ${ }^{*[a]}$ \\ This article is dedicated in memoriam to Professor José Barluenga Mur.
}

\begin{abstract}
The photolysis of iodide anion promotes the reaction of carbon dioxide with hydrogen sulfide or thiols to give quantitatively formic acid and sulfur or disulfides. The reaction takes place in acetonitrile and aqueous solutions, at atmospheric pressure and room temperature, by irradiation with a low pressure mercury lamp. This transition metal-free photocatalytic process for $\mathrm{CO}_{2}$-capture coupled to $\mathrm{H}_{2} \mathrm{~S}$-removal may have been relevant as a prebiotic carbon dioxide fixation.
\end{abstract}

Hydrated electrons are of fundamental importance in chemical, physical and biological systems, and their complex reactivity and elusive dynamics has been the subject of intensive research. ${ }^{[1]}$ Hydrated electrons are the simplest reductants in aqueous solution, and can be efficiently scavenged by organic compounds with reduction potentials less negative than $\mathrm{E}^{\circ}\left(\mathrm{aq} / \mathrm{e}^{-}\right.$ aq) $=-2.87 \mathrm{~V}$ versus the standard hydrogen electrode $(\mathrm{SHE})^{[2]}$ to open reaction paths alternative to conventional reductions. ${ }^{[3]}$ Notwithstanding, hydrated electrons have been scarcely applied in preparative processes ${ }^{[4]}$ probably due to their reactivity and transient nature, as well as the limitations posed by the common methods for their generation namely, water radiolysis and irradiation of the charge-transfer-to-solvent absorption bands of halide anions in the UVC region (200-290 nm). By contrast, ammoniated electrons, which are available as solutions of alkali metals in ammonia, have found a wide use as reducing reagents. ${ }^{[5]}$

Carbon dioxide $\left(\mathrm{E}^{\circ}\left(\mathrm{CO}_{2} / \mathrm{CO}_{2}^{--}\right)=-1.9 \mathrm{~V} \text { vs. SHE}\right)^{[2]}$ reacts with hydrated electrons with a rate constant of $7.7 \cdot 10^{9} \mathrm{~L} \mathrm{~mol}^{-1} \mathrm{~s}$ ${ }^{\left.1,{ }^{[6]}\right]}$ which provide interesting opportunities for carbon dioxide reduction. ${ }^{[7]}$ Notwithstanding, the one-electron reduction of carbon dioxide requires, in order to be productive, of efficient hydrogen and proton transfer steps ${ }^{[8]}$ which prevent the carbon dioxide radical anion, a strong reductant itself, to deactivate by reaction with other species in solution, and of efficient scavengers for the oxidized species formed in the generation of hydrated electrons, which would otherwise compete with carbon dioxide as an electron sink. The redox potentials and reaction rates of the different intermediates involved in this complex system must then be finely tuned to conduct the reaction toward the desired transformation.

Thiols 1 seemed to us promising reagents for carbon dioxide

[a] Dr. Mateo Berton, Prof. Dr. Rossella Mello, Prof. Dr. María Elena González-Núñez

Departamento de Química Orgánica

Universidad de Valencia

Avda. Vicente Andrés Estellés s.n.

46100-Burjassot (Valencia) Spain

E-mail: elena.gonzalez@uv.es

Supporting information for this article is given via a link at the end of the document. reduction when coupled to the photolysis of the iodide anion as a source of hydrated electrons and iodine atoms. ${ }^{\left[{ }^{9]}\right.}$ Indeed, thiols 1 are known to behave as hydrogen atom donors ${ }^{[10]}$ toward the radical anion of carbon dioxide $\mathbf{I}$ in the gas phase to give formate anion and thiyl radicals II, ${ }^{[11]}$ and as reductants toward iodine to give disulfides $\mathbf{2}$ and hydrogen iodide through sulfenyl iodide intermediates III which undergo $\mathrm{S}_{\mathrm{N}} 2$ at the sulfur atom by a second molecule of thiol. ${ }^{[12]}$ The assembly of these reactions ${ }^{[9-12]}$ outlines the photocatalytic cycle for the reduction of carbon dioxide to formic acid shown in Scheme 1. The present concern about the increasing anthropogenic emissions of carbon dioxide to the atmosphere, and the interest of the reductive transformations of carbon dioxide ${ }^{[13,14]}$ prompted us to explore this possibility by using 2-mercaptoethanol (1a) as a model substrate, and in acetonitrile- $d_{3}$ and water as solvents.

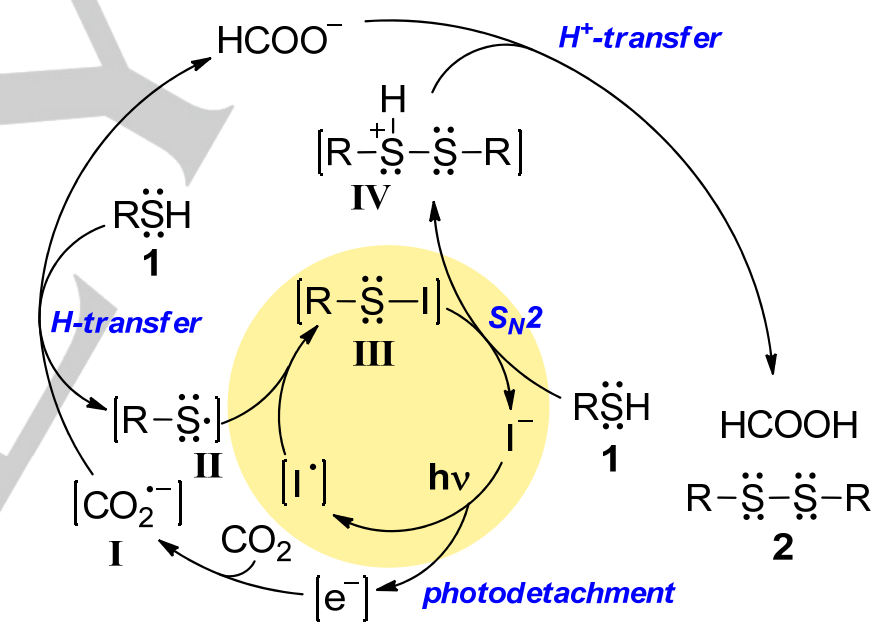

Scheme 1. Reaction scheme devised ${ }^{[9-12]}$ for the iodide photocatalyzed reduction of carbon dioxide with thiols 1 .

The reactions were performed by placing $5 \mathrm{~mL}$ of degassed acetonitrile- $d_{3}$ or aqueous solutions of 2-mercaptoethanol (1a) and lithium or potassium iodide, respectively, in a quartz test tube purged with carbon dioxide, and cooling the system in an ice-water bath under carbon dioxide (ca. 20 psi) for 20 min with magnetic stirring. The tube was firmly capped with a rubber septum at $0{ }^{\circ} \mathrm{C}$ under carbon dioxide at atmospheric pressure, then fixed to the motor unit of a rotary evaporator, and irradiated with a $36 \mathrm{~W}$ low pressure mercury lamp $(\lambda=254 \mathrm{~nm})$ placed in parallel $2 \mathrm{~cm}$ above the test tube, under rotation and with magnetic stirring at room temperature. The reaction mixtures were suspensions of variable amounts of a pale yellow solid, smelled of hydrogen sulphide, and showed no overpressure. Aliquots of the decanted solutions were diluted with stock 
Table 1. lodide-photocatalyzed reduction of carbon dioxide with 2-mercaptoethanol (1a). ${ }^{[a]}$

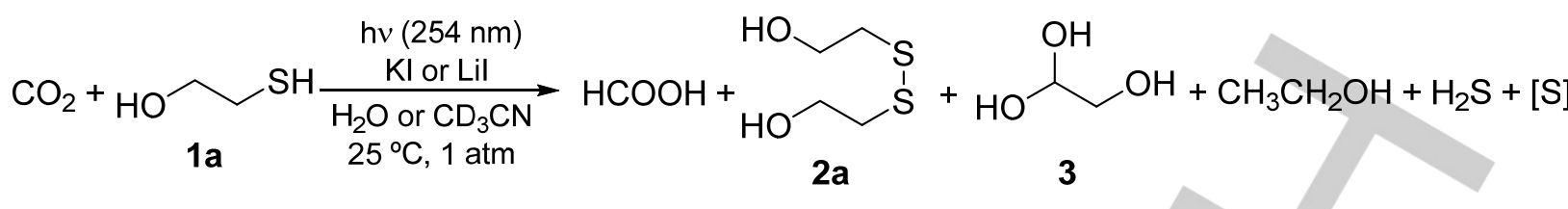

\begin{tabular}{|c|c|c|c|c|c|c|c|c|c|c|c|}
\hline \multirow[t]{2}{*}{ Run } & \multirow[t]{2}{*}{ Solv. } & \multirow[t]{2}{*}{ Substrate } & \multirow{2}{*}{$\begin{array}{l}\text { Conc. } \\
\text { (M) }\end{array}$} & \multirow{2}{*}{$\stackrel{\mathrm{t}}{\mathrm{min}})$} & \multirow{2}{*}{$\begin{array}{c}\left.\mathrm{M}\right|^{[\mathrm{b}]} \\
(\mathrm{mol} \%)\end{array}$} & \multirow{2}{*}{$\begin{array}{l}\text { Molar ratio } \\
\mathrm{CO}_{2}: \text { Subs. }{ }^{[c]}\end{array}$} & \multirow{2}{*}{$\begin{array}{c}\text { Conv. } \\
(\%)\end{array}$} & \multicolumn{4}{|c|}{ Product yield ${ }^{[d]}(\%)$} \\
\hline & & & & & & & & $\mathrm{HCOOH}$ & $2 a$ & 3 & $\mathrm{CH}_{3} \mathrm{CH}_{2} \mathrm{OH}$ \\
\hline 1 & $\mathrm{CD}_{3} \mathrm{CN}$ & $1 a$ & 0.19 & 180 & 30 & $1.3: 1$ & 100 & 64 & 91 & -- & $<1$ \\
\hline 2 & $\mathrm{CD}_{3} \mathrm{CN}$ & $1 \mathrm{a}$ & 0.068 & 180 & 10 & $3.5: 1$ & 100 & 100 & 72 & -- & -- \\
\hline 3 & $\mathrm{CD}_{3} \mathrm{CN}$ & $1 a$ & 0.068 & 60 & 10 & $3.5: 1$ & 100 & 05 & 99 & -- & -- \\
\hline 4 & $\mathrm{H}_{2} \mathrm{O}$ & $1 \mathrm{a}$ & 0.034 & 180 & 10 & $2.2: 1$ & 92 & 100 & 26 & 42 & 15 \\
\hline 5 & $\mathrm{H}_{2} \mathrm{O}$ & $1 a$ & 0.034 & 30 & 30 & $2.2: 1$ & 75 & 48 & 74 & 14 & 12 \\
\hline 6 & $\mathrm{H}_{2} \mathrm{O}$ & $1 \mathrm{a}$ & 0.034 & 90 & 30 & $2.2: 1$ & 90 & 89 & 55 & 32 & 11 \\
\hline 7 & $\mathrm{H}_{2} \mathrm{O}$ & $1 \mathrm{a}$ & 0.034 & 180 & 30 & $2.2: 1$ & 100 & 152 & 33 & 53 & 14 \\
\hline $8^{e}$ & $\mathrm{H}_{2} \mathrm{O}$ & $2 a$ & 0.03 & 180 & 50 & $2.2: 1$ & 51 & 69 & -_[e] & 57 & 6 \\
\hline $9^{f}$ & $\mathrm{CD}_{3} \mathrm{CN}$ & $2 a$ & 0.034 & 180 & 50 & $7: 1$ & 9 & 43 & $-[f]$ & -- & -- \\
\hline
\end{tabular}

[a] Reactions were performed with a $36 \mathrm{~W}$ low pressure mercury lamp at $25^{\circ} \mathrm{C}$ and atmospheric pressure in acetonitrile- $d_{3}$ and water. Hydrogen sulfide and sulfur were not quantified. ${ }^{[b]}$ Lil was used in acetonitrile- $d_{3}$, and $\mathrm{KI}$ in aqueous solution. ${ }^{[c]}$ The molar ratio $\mathrm{CO}_{2}: 1$ a was determined from the solubility reported for carbon dioxide in propionitrile at $25^{\circ} \mathrm{C},{ }^{[15]}$ and water at $0{ }^{\circ} \mathrm{C} \cdot{ }^{[16]}\left[{ }^{[d]}\right.$ Product yields are relative to the converted thiol $1 \mathrm{a}\left(\mathrm{CO}_{2}+2 \mathrm{RSH}=\mathrm{HCOOH}+\mathrm{RSSR}\right)$. The figures are the average of three independent experiments and are within $15 \%$ of standard deviation. [e] Thiol 1a was formed as a product in water (17 \%). ${ }^{[f]}$ Thiol $1 \mathrm{a}$ was not found as a product in $\mathrm{CD}_{3} \mathrm{CN}$.

solutions of phenol as an external standard, and analyzed by ${ }^{1} \mathrm{H}$ and ${ }^{13} \mathrm{C}$ NMR spectroscopy. The reaction products were identified by comparison with authentic samples. The product yields relative to converted thiol $\mathbf{1 a}$ were quantified from the integrals of their ${ }^{1} \mathrm{H}$ NMR signals and those of the external standard. The results are shown in Table 1. Molar ratios carbon dioxide:1a were estimated from the solubility reported for carbon dioxide $(1 \mathrm{~atm})$ in propionitrile at $25^{\circ} \mathrm{C}^{[15]}$ and water at $0{ }^{\circ} \mathrm{C}^{[16]}$ ( 0.241 and $0.075 \mathrm{M}$, respectively). The experimental procedures and spectra are collected in the Supplementary Material.

The irradiation of a $0.19 \mathrm{M}$ solution of 2-mercaptoethanol (1a) in acetonitrile- $d_{3}$ saturated with carbon dioxide (molar ratio carbon dioxide:1a 1.3:1), in the presence of $30 \mathrm{~mol} \%$ of lithium iodide, led to the quantitative conversion of thiol 1a into the corresponding 2,2'-disulfanediylbis(ethan-1-ol) (2a), to give $64 \%$ yield of formic acid in relation to the converted thiol 1a (Run 1, Table 1). This result suggested that thiol 1a partially undergoes unproductive disproportion under our reaction conditions. ${ }^{[17,18]}$ In order to improve the competitiveness of carbon dioxide we performed the experiment with a $0.068 \mathrm{M}$ solution of thiol 1a (molar ratio carbon dioxide:1a 3.5:1) under the same conditions. The reaction led to the quantitative conversion of thiol $\mathbf{1 a}$ to give formic acid (100 \%) and disulfide 2a (72 \%) (Run 2, Table 1).

The reaction was complete after $1 \mathrm{~h}$, giving in this case $95 \%$ of formic acid (Run 3, Table 1). No reduction of carbon dioxide was observed in the absence of either iodide salt or 2- mercaptoethanol (1a). Oxalic acid, formaldehyde and methanol were not detected as products in the reaction mixtures.

Once we proved that the photolysis of the iodide anion efficiently promoted the reduction of carbon dioxide to formic acid by thiol $1 \mathrm{a}$ in an acetonitrile- $d_{3}$ solution, we explored the reaction in aqueous medium. The irradiation of a $0.034 \mathrm{M}$ aqueous solution of 2-mercaptoethanol (1a) with $10 \mathrm{~mol} \%$ of potassium iodide and saturated with carbon dioxide (molar ratio carbon dioxide:1a 2.2:1) led to a $92 \%$ conversion of thiol 1a to give formic acid (100\%), 1,2-dihydroxyethanol (3) (42\%), disulfide $2 \mathbf{a}(26 \%)$, ethanol (15\%), and unquantified amounts of hydrogen sulfide and sulfur (Run 6, Table 1). 1,2Dihydroxyethanol (3) was identified from the ${ }^{1} \mathrm{H}$ NMR signals at $\delta 3.52$ (d) and 5.06 (t) ppm, correlated to signals at $\delta 64.98$ and $90.20 \mathrm{ppm}$ in the ${ }^{13} \mathrm{C}$ NMR spectrum, and was confirmed by comparison with an authentic sample. This result shows that the reduction of carbon dioxide to formic acid by thiol 1a proceeds efficiently in aqueous medium as well, yet reveals significant changes in the reaction course.

In order to track the formation of the different products in aqueous medium, we performed a series of experiments with variable reaction times (Runs 5-7, Table 1), by using $30 \mathrm{~mol} \%$ of potassium iodide to minimize the direct photolysis of thiol $\mathbf{1 a}$ (the absorbances at $254 \mathrm{~nm}$ for iodide and thiol 1a under these reaction conditions were 0.3384 and 0.0319 , respectively). The reaction performed for 30 min (Run 5, Table 1) showed a $75 \%$ conversion of thiol $1 \mathrm{a}$ to give disulfide $2 \mathrm{a}(74 \%)$, formic acid 
(48\%), and 1,2-dihydroxyethanol (3) (14\%). By extending the irradiation time to 90 and 180 min (Runs 6 and 7, Table 1), we observed increasing yields of formic acid and 1,2dihydroxyethanol (3), which reached $152 \%$ and $53 \%$, respectively, associated to the progressive depletion of disulfide $\mathbf{2 a}$ and increasing conversion of thiol $\mathbf{1 a}$.

These results show that thiol $\mathbf{1 a}$ converts into disulfide $\mathbf{2 a}$ at the early stages of the reaction and, thereby, that disulfide $\mathbf{2 a}$ is able to reduce carbon dioxide to formic acid under our reaction conditions. This fact was ascertained by irradiating a $0.034 \mathrm{M}$ aqueous solution of disulfide $\mathbf{2 a}$ with $50 \mathrm{~mol} \%$ of potassium iodide saturated with carbon dioxide (Run 8, Table 1), which gave formic acid (69\%), 1,2-dihydroxyethanol (3) (57\%), ${ }^{[19]}$ thiol 1a $(17 \%)$, ethanol (6\%), and unquantified amounts of sulfur and hydrogen sulfide, with a $51 \%$ conversion of the starting disulfide 2a (Run 8, Table 1).

The formation of thiol $1 \mathrm{a}$ and 1,2-dihydroxyethanol (3) in this reaction ${ }^{[19]}$ evidenced that the actual reductants of carbon dioxide under our reaction conditions are intermediate $\mathrm{S}-\mathrm{H}$ functionalities formed from disulfide $\mathbf{2 a}$ at the expense of the side-chain hydrogen atoms. This process proved to be very sensitive to the solvent. Indeed, the reaction of disulfide $2 \mathrm{a}$ with carbon dioxide in acetonitrile- $d_{3}$ under our standard conditions converted only $9 \%$ of disulfide $2 a$ to give formic acid in $43 \%$ yield as the only product (Run 9 , Table 1 ).

$$
\begin{aligned}
& \mathrm{h} v(254 \mathrm{~nm}) \\
& \mathrm{KI}(10 \mathrm{~mol} \%) \mathrm{H}_{2} \mathrm{O} \\
& \begin{array}{cc}
\mathrm{CO}_{2}+\mathrm{H}_{2} \mathrm{~S} \underset{ }{\stackrel{\left.2 \mathrm{H}_{2} \mathrm{~S}\right]=0.023 \mathrm{M}}{\mathrm{CO}_{2}: \mathrm{H}_{2} \mathrm{~S} 3.2: 1}} \mathrm{HCOOH}+[\mathrm{S}] \\
\end{array}
\end{aligned}
$$

Finally, we performed the reaction with hydrogen sulfide as a hydrogen donor. ${ }^{[20]}$ The reduction of carbon dioxide by hydrogen sulfide has been frequently hypothesized as a prebiotic process for carbon dioxide fixation, ${ }^{[21]}$ yet the actual reaction conditions to perform this transformation have not been described up to now. The irradiation of a $0.023 \mathrm{M}$ aqueous solution of hydrogen sulfide saturated with carbon dioxide (molar ratio carbon dioxide:hydrogen sulfide $3.2: 1$ ) in the presence of $10 \mathrm{~mol} \%$ of potassium iodide under our standard reaction conditions led to a suspension of elemental sulfur. The ${ }^{1} \mathrm{H}$ and ${ }^{13} \mathrm{C}$ NMR analyses of the decanted solution showed the formation of formic acid in quantitative yields relative to the starting hydrogen sulfide (Equation 1). The reaction in the absence of potassium iodide did not lead to formic acid.

The basic chemical steps devised in Scheme $1^{[9-12]}$ rationalize the experimental results shown in Table 1 and Equation 1, yet further research is required to ascertain the actual reaction paths, intermediates, and competing processes under the different reaction conditions. For instance, the involvement of solvated electrons versus inner-sphere electron transfer, the role of protons as competitive electron sinks, ${ }^{[22]}$ the possible intermediacy of species like the radical anions of thiol 1 and iodine, the radical adducts [RSH.l] and [RSH.SR ], or the $\left[{ }_{3}{ }^{-}\right]$anion, as well as the possible alternative reaction paths of carbon dioxide, are significant mechanistic issues requiring detailed investigation.

The impact of the solvent on the formation of $\mathrm{S}-\mathrm{H}$ functionalities at the expense of side-chain hydrogen atoms of disulfide $\mathbf{2 a}$ is an interesting feature of the results shown in Table 1. The reaction probably proceeds through electron capture by $2 \mathbf{a}$ followed by dissociation of the C-S or S-S $\sigma$-bonds of disulfide 2a radical anion, ${ }^{[23]}$ hydrogen abstraction from the methylene group $\alpha$ to the sulfur atom by the radical intermediate, collapse of the C-centered radical with the iodine atom, and hydrolysis of the resulting $\alpha$-iodoalcohol to give 1,2dihydroxyethanol (3) and restore the iodide anion into the solution. The hydrolysis step and the solvation of the anionic intermediates involved in this sequence would account for the better performance of this reaction in water compared to acetonitrile. Hydrogen abstraction by thiyl radicals from aminoacid side-chains has been recently shown to occur in the photo-degradation of peptides and aminoacids. ${ }^{[24]}$

In summary, we have described a transition metal-free photocatalytic process for reducing carbon dioxide to formic acid with thiols 1 and hydrogen sulfide, in which iodine atoms mediate the transfer of electrons from the sulfur atom to carbon dioxide. This primary photosynthetic reaction involving iodide salts, carbon dioxide, and hydrogen sulfide may have been relevant as a prebiotic process for carbon dioxide fixation. ${ }^{[21]}$ This novel $\mathrm{CO}_{2}$-capture $/ \mathrm{H}_{2} \mathrm{~S}$-removal process may be further improved by using electron and hydrogen donors photoactivated in the visible region. ${ }^{[3]}$ Indeed, the reactions described herein may be involved nowadays in the chemistry of anoxic natural waters, in which dissolved organic matter would be the source of hydrated electrons. ${ }^{[3,25]}$

\section{Acknowledgements}

Financial support from the Spanish Ministerio de Economía y Competitividad (CTQ2013-47180-P), and Fondos FEDER is gratefully acknowledged. MB thanks the Spanish Ministerio de Economía y Competitividad for a fellowship (BES-2011-043933). We thank the SCSIE (Universidad de Valencia) for access to their instrumental facilities.

Keywords: carbon dioxide chemistry $\bullet$ photocatalysis $•$

[1] R. M. Young, D. M. Neumark, Chem. Rev. 2012, 112, 5553-5577.

[2] P. Wardman, J. Phys. Chem. Ref. Data 1989, 18, 1637-1755.

[3] a) M. Brautzsch, C. Kerzig, M. Goez, Green Chem. 2016, 18, 47614771. b) C. Kerzig, M. Goez, Chem. Sci. 2016, 7, 3862-3868. c) J. D. Sutherland, Angew. Chem. Int. Ed. 2016, 55, 104-121. d) C. Kerzig, M. Goez, Phys. Chem. Chem. Phys. 2015, 16, 13829-13836. e) C. Kerzig, M. Goez, Phys. Chem. Chem. Phys. 2014, 16, 25342-25349. f) M Goez, C. Kerzig, R. Naumann, Angew. Chem. Int. Ed. 2014, 53, 99149916. g) D. Ritson, J. D. Sutherland, Nature Chem. 2012, 4, 895-899.

[4] a) X. Liu, T. Zhang, L. Wang, Y. Shao, L. Fang, Chem. Eng. J. 2015 260, 740-748. b) H. Park, C. D. Vecitis, J. Cheng, W. Choi, B. T. Mader, M. E. Hoffmann, J. Phys. Chem. A 2009, 113, 690-696. c) Y. Qu, C. Zhang, F. Li, J. Chen, Q. Zhou, Water Res. 2010, 44, 2939-2947. d) H. 
Park, C. D. Vecitis, J. Cheng, N. F. Dalleska, B. T. Mader, M. R Hoffmann, Photochem. Photobiol. Sci. 2011, 10, 1945-1953.

[5] a) P. W. Rabideau, Z. Marcinow, Organic Reactions 2004, 42:1, 1-334. b) D. Caine, Organic Reactions 2011, 23:1, 1-258.

[6] G. V. Buxton, C. L. Greenstock, W. P. Helman, A. B. Ross, J. Phys. Chem. Ref. Data 1988, 17, 513-886.

[7] a) L. Zhang, D. Zhu, G. M. Nathanson, R. J. Hamers, Angew. Chem. Int Ed. 2014, 53, 9746-9750. b) O. P. Balaj, C. K. Siu, I. Balteanu, M. K Beyer, V. E. Bondybey, Chem. Eur. J. 2004, 10, 4822-4830.

[8] E. E. Benson, C. P. Kubiak, A. J. Sathrum, J. M. Smieja, Chem. Soc. Rev. 2009, 38, 89-99.

[9] a) L. Lehr, M. T. Zanni, C. Frischkorn, R. Weinkauf, D. M. Neumark, Science 1999, 284, 635-638. b) M. J. Blandamer, M. A. Fox, Chem. Rev. 1970, 70, 59-93.

[10] F. Dénès, M. Pichowicz, G. Povie, P. Renaud, Chem. Rev. 2014, 114 , 2587-2693.

[11] a) R. F. Höckendorf, C. -K. Siu, C. van der Linde, O. P. Balaj, M. K. Beywe, Angew. Chem. Int. Ed. 2010, 49, 8257-8259. b) R. F. Höckendorf, Q. Hao, Z. Sun, B. S. Fox-Beyer, Y. Cao, O. P. Balaj, V. E. Bondybey, C. -K. Siu, M. K. Beyer, J. Phys. Chem. A 2012, 116, 3824 3835. c) D. A. Armstrong, Q. Sun, G. N. R. Tripathi, R. H. Schuler, D. McKinnon, J. Phys. Chem. 1993, 97, 5611-5617. d) P. S. Surdhar, S. P Mezyk, D. A. Armstrong, J. Phys. Chem. 1989, 93, 3360-3363.

[12] a) J. P. Danehy, M. Y, Oester, J. Org. Chem. 1967, 32, 1491-1495. b) J. P. Danehy, B. T. Doherty, C. P. Egan, J. Org. Chem. 1971, 36, 25252530.

[13] a) J. L. White, M. F. Baruch, J. E. Pander III, Y. Hu, I. C. Fortmeyer, J. E. Park, T. Zhang, K. Liao, J. Gu, Y. Yan, T. W. Shaw, E. Abelev, A. B. Bocarsly, Chem. Rev. 2015, 115, 12888-12935. b) A. Goeppert, M. Czaun, J. -P. Jones, G. K. S. Prakash, G. A. Olah, Chem. Soc. Rev. 2014, 43, 7995-8048.

[14] Some recent references on carbon dioxide reduction which illustrate different approaches to this subject: (a) C. Liu, B. C. Colón, M. Ziesack, P. A. Silver, D. G. Nocera, Science, 2016, 352, 1210-1213. (b) M. Ma, B. J. Trzesniewski, J. Xie, W. A. Smith, Angew. Chem. Int. Ed. 2016, 55 9748-9752. (c) T. E. Rosser, C. D. Windle, E. Reisner, Angew. Chem Int. Ed. 2016, 55, 7388-7392. (d) L. Chen, Z. Guo, X. -G. Wei, C. Gallenkamp, J. Bonin, E. Anxolabéhère-Mallart, K. -C. Lau, M. Robert, J. Am. Chem. Soc. 2015, 137, 10918-10921. (e) N. Hollingsworth, S. F R. Taylor, M. T. Galante, J. Jacquemin, C. Longo, K. B. Holt, N. H. deLeeuw, C. Hardacre, Angew. Chem. Int. Ed. 2015, 54, 14164-14168. (f) S. Lin, C. S. Diercks, Y. -B. Zhang, N. Kornienko, E. M. Nichols, Y Zhao, A. R. Paris, D. Kim, P. Yang, O. M. Yaghi, C. J. Chang, Science 2015, 349, 1208-1213. (g) C. Liu, J. J. Gallagher, K. K. Sakimoto, E. M. Nichols, C. J. Chang, M. C. Y. Chang, P. Yang, Nano Lett. 2015, 15, 3634-3639. (h) C. W. Machan, M. D. Sampson, C. P. Kubiak, J. Am. Chem. Soc. 2015, 137, 8564-8571. (i) X. Min, M. W. Kanan, J. Am. Chem. Soc. 2015, 137, 4701-4708. (j) Y. Tamaki, K. Koike, O. Ishitani, Chem. Sci. 2015, 6, 7213-7221. (k) J. Graciani, K. Mudiyanselage, F. Xu, A. E. Baber, J. Evans, S. D. Senanayake, D. J. Stacchiola, P. Liu, J. Hrbek, J. Fernández-Sanz, J. A. Rodríguez, Science 2014, 345, 546-
550. (I) K. Schuchmann, V. Müller, Science 2013, 342, 1382-1385. (m) H. Li, P. H. Opgenorth, D. G. Wernick, S. Rogers, T.-Y. Wu, W. Higashide, P. Malati, Y.-X. Huo, K. M. Cho, J. C. Liao, Science, 2012, 335, 1596. (n) R. Angamuthu, P. Byers, M. Lutz, A. L. Spek, E. Bouwman, Science, 2010, 327, 313-315.

[15] P. G. T. Fogg, Ed. IUPAC Solubility Data Series Volume 50. Carbon Dioxide in Non-Aqueous Solvents at Pressures Less Than 200 KPA (Pergamon Press, 1992).

[16] J. J. Carroll, J. D. Slupsky, A. E. Mather, J. Phys. Chem. Ref. Data 1991, 20, 1201-1209.

[17] The photolysis of thiol $1 \mathrm{a}$ and lithium iodide in acetonitrile- $d 3$ led to complete conversion of $1 \mathbf{a}$ into disulfide $\mathbf{2 a}(71 \%)$, ethanol $(8 \%)$, and unquantified amounts of sulfur and hydrogen sulfide, while the photolysis of thiol 1a under the same conditions proceeded with only $41 \%$ conversion to give the same products. ${ }^{[18]}$ See the Supplementary Material for details.

[18] W. A. Pryor, E. G. Olsen, J. Am. Chem. Soc. 1978, 100, 2852-2856.

[19] 1,2-Dihydroxyethanol (3) was also a product from the photolysis of aqueous $1 \mathrm{a}$ both in the presence and absence of potassium iodide (30 mol \%), under argon atmosphere. Conversely, the same reactions performed in acetonitrile- $d_{3}$ gave only disulfide $\mathbf{2 a}$, ethanol, hydrogen sulfide and sulfur ${ }^{[17]}$ as products. See the Supplementary Material for details.

[20] References on the use of hydrogen sulfide as a hydrogen source: (a) $X$ Zhong, J. Han, B. Seger, H. Chen, G. M. Lu, C. Li, L. Wang, Angew. Chem. Int. Ed. 2014, 53, 4399-4403. (b) U. V. Kawade, R. P. Panmand, Y. A. Sethi, M. V. Kulkami, S. K. Apte, S. D. Naik, B. B. Kale, RSC Adv. 2014, 4, 49295-49302. (c) A. K. Apte, S. N. Garaje, M. Valant, B. B. Kale, Green Chem. 2012, 14, 1455-1462. (d) G. Yu, H. Wang, K. T. Chuang, Energy Fuels 2009, 23, 2184-2191. (e) I. Tsuji, A. Kudo, Angew. Chem. Int. Ed. 2005, 44, 3565-3568.

[21] E. T. McGuinness, Chem. Rev. 2010, 110, 5191-5215.

[22] Hydrogen is expected as a side product from either thiol disproportion under irradiation and reductive conditions, or reduction of protons by solvated electrons. However, the high yields of formic acid in relation to converted thiol 1 (Table 1) suggest that these are minor processes under our reaction conditions. Concerning the generation of hydrogen under similar reductive conditions, see reference $7 \mathrm{a}$.

[23] S. Antonello, R. Benassi, G. Gavioli, F. Taddei, F. Maran, J. Am. Chem. Soc. 2002, 124, 7529-7538.

[24] a) T. Nauser, W. H. Koppenol, C. Schöneich, J. Phys. Chem. B 2012 116, 5329-5341. b) O. Mozziconacci, B. A. Kermin, C. Schöneich, J. Phys. Chem. B 2011, 115, 12287-12305.

[25] a) W. Wang, O. C. Zafiriou, I. -Y. Chan, R. G. Zepp, N. V. Blough, Environ. Sci. Technol. 2007, 41, 1601-1607. b) T. E. Thomas-Smith, N. V. Blough, Environ. Sci. Technol. 2001, 35, 2721-2726. 
Layout 2:

\section{COMMUNICATION}

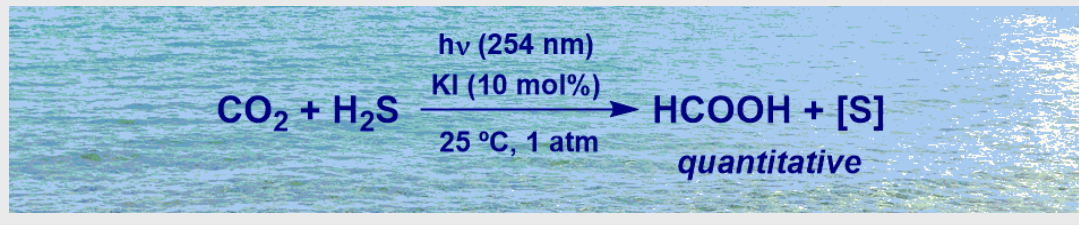

Connecting the dots: the electron photodetachment from iodide anion, the hydrogen transfer from thiols to carbon dioxide radical anion, and the oxidation of thiols by iodine, define a robust and transition metal-free photocatalytic method for the reduction of carbon dioxide to formic acid by thiols and hydrogen sulfide at atmospheric pressure in aqueous and acetonitrile solution.
Mateo Berton, Rossella Mello, María Elena González-Núñez*

Page No. - Page No.

lodide-photocatalyzed Reduction of Carbon Dioxide to Formic Acid with Thiols and Hydrogen Sulfide

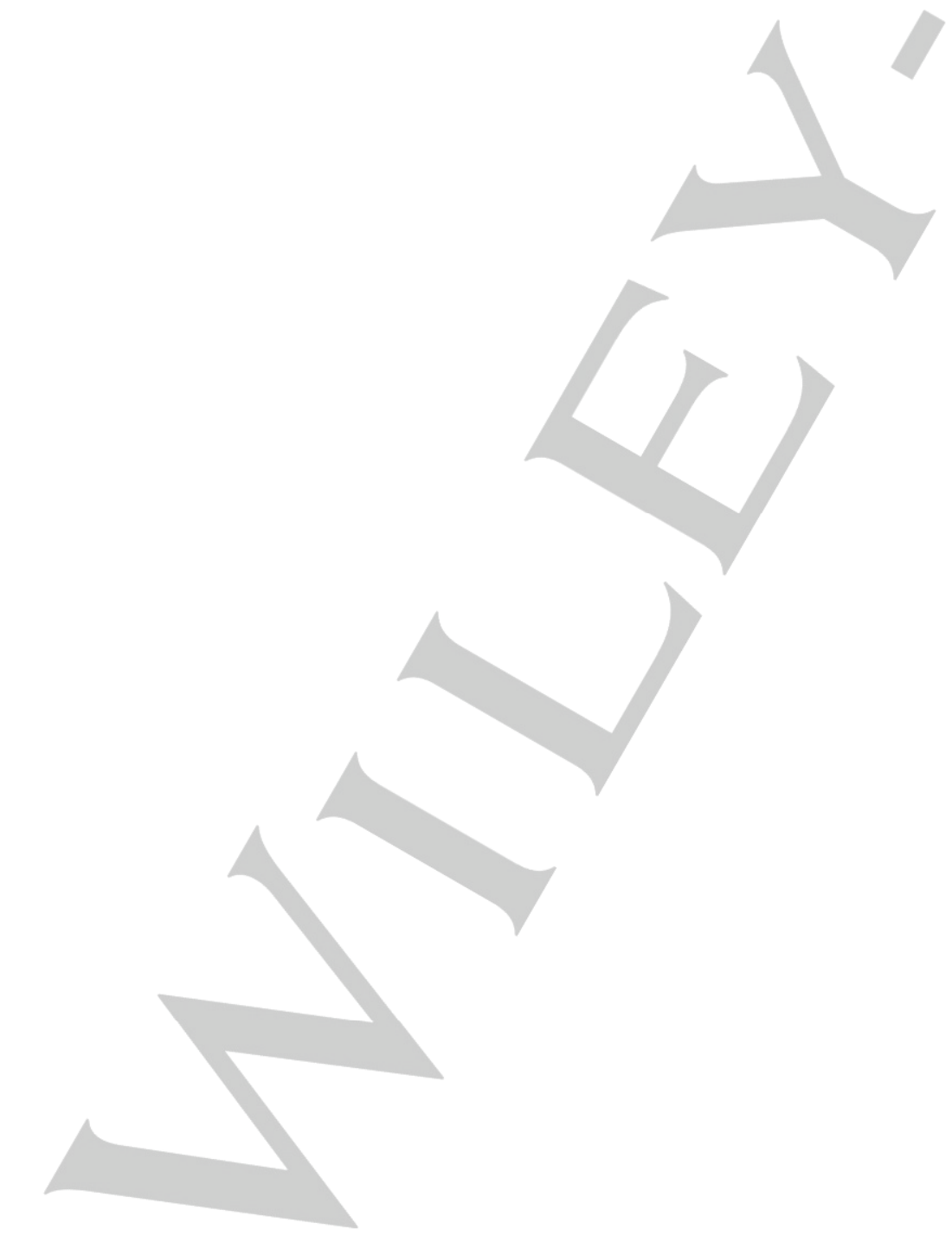

